\title{
Observed Characteristics and Modeled Emissions of Transit Buses on Ramps
}

\author{
Haobing Liu ${ }^{1}$, Shuyang Zhang ${ }^{2}{ }^{*}$, Guojun Chen ${ }^{2}$ and Qian Gao ${ }^{3}$ \\ 1 School of Civil and Environmental Engineering, Georgia Institute of Technology, Atlanta, GA 30332, USA; \\ haobing.liu@gatech.edu \\ 2 School of Transportation, Wuhan University of Technology, Wuhan 430063, China; \\ guojun.chen@whut.edu.cn \\ 3 The Key Laboratory of Road and Traffic Engineering, Ministry of Education, Tongji University, Shanghai \\ 201804, China; 1910920@tongji.edu.cn \\ * Correspondence: zhangshuyang@whut.edu.cn
}

Received: 28 February 2020; Accepted: 31 March 2020; Published: 1 April 2020

\begin{abstract}
On-ramps and off-ramps that serve as connections between high-speed facilities and arterials are potential hotspots for vehicle emissions. The engine load associated with grade and acceleration on uphill ramps can lead to significant emissions of criteria pollutants and greenhouse gases (GHGs) over a short distance. This study explores transit bus operations and emissions at ramps using Global Positioning System (GPS) data collected from Detroit transit buses. Ramp-associated operating data are extracted from the vehicle traces using ArcGIS and assigned to the applicable United States Environmental Protection Agency's emission rates, i.e., EPA's Motor Vehicle Emission Simulator (MOVES). The results show that transit bus emission rates for on-ramp operations at $40 \mathrm{mph}(64.37 \mathrm{~km} / \mathrm{h})$ are about double the average emission rate on the MOVES highway cycles. For lower on-ramp speeds $(<64.37 \mathrm{~km} / \mathrm{h})$, as average speeds decrease, on-ramp emission rates drop roughly to the highway emission rates given the less aggressive acceleration noted in the data. Off-ramp emission rates are approximately half of the highway emission rates. The study also finds that post-ramp acceleration, right after buses enter the highway from the on-ramp, contributes to high emissions, because of the high-speed and high-power operations. This is true for the loop on-ramp, where the bus emission rate after entering the highway is higher than the emissions associated with driving on the ramp. On-ramp emissions are found to vary across a wide range of conditions, indicating that further study and more data are needed to explore the overall impacts of on-ramp and post-ramp activity in emissions modeling. A sensitivity analysis of ramp grade effect on emission indicates that ramp grade should be specifically considered in project-level analyses. The research results are useful for understanding ramp driving characteristics, the potential impacts of ramp grade on emissions, and the ramp hotspot analysis.
\end{abstract}

Keywords: ramp; transit bus; operations; emissions; MOVES; GPS

\section{Introduction}

The ramp acts as a connection between highways and local roads. Significant differences in operating conditions exist between the roadway facilities that ramps connect, in terms of speed, elevation, and roadway configuration. Hence, vehicles accelerate, decelerate, and navigate up and down on these ramps. The Motor Vehicle Emission Simulator (MOVES), the regulatory emission model invented by the U.S. Environmental Protection Agency [1], defines ramp activity as vehicle operations that occur between the unrestricted road (local road) and the restricted road (highway/freeway). MOVES assumes that ramp activity comprises about $8 \%$ of nationwide freeway operating hours for all 
source types [1], based upon the ramp fraction value originally developed by Systems Applications International, Inc. for the MOBILE model [2]. The large fraction of ramp mileage and the high-power operations that occur on ramps lead to a significant contribution of ramps to the transportation emissions inventory. Ramps are potential emissions hotspots if significant localized emissions occur at these locations. In Environmental Protection Agency (EPA) project-level Particulate Matter (PM) conformity hotspot analysis guidance [3], ramps are presented as an introductory example for MOVES and AERMOD (American Meteorological Society/Environmental Protection Agency Regulatory Model) analysis.

Generally, light-duty vehicles on-ramp emit about two to three times more than vehicles on highways (excluding ramps) and local cycles with an average speed greater than $30 \mathrm{mph}(48.28$ $\mathrm{km} / \mathrm{h}$ ) [4]. Despite the potential impact of ramps on emissions and air quality, relevant literature is quite limited. Liu et al. [5] compared energy and emissions of the passengers using aircraft, bus, and automobile in the U.S. To collect the operations data for the cases of Detroit on-ramp, Thornton et al. [6] used a laser rangefinder, presented speed-distance plots of the on-ramp activity, and estimated the emissions of ramp metering schemes via the MEASURE emission rate model. This research was a first step in understanding ramp operations and emissions, although the extension of these results to the general description of on-ramp activities is limited.

Recently, the influence of ramp metering on emission reduction has been considered in research. Bae et al. [7] adopted ramp metering to evaluate the changes in traffic flow and $\mathrm{CO}_{2}$ emission variations, which suggested that ramp metering makes a great contribution to the reduction of $\mathrm{CO}_{2}$ emissions. Du et al. $[8,9]$ found that the isolated and integrated ramp metering approaches can improve mobility and reduce travel delay. However, relevant studies are limited and emissions vary with vehicle type. The emissions of light-duty vehicles have been studied a lot [10-13], but research about the emission of heavy-duty vehicles is relatively less.

The research presented in this paper assesses the observed on-road operations and modeled emissions of transit bus activity on-ramps. The road grade has been considered in the model in view of its great influence [14,15]. Analyses include on-ramps and off-ramps, in both diagonal and loop ramp configurations [16]. The analyses employ the Global Positioning System (GPS) data, including second-by-second speed and position data, collected from a fleet of the Detroit transit system. Researchers extracted ramp-associated operations from the data using known ramp locations and Geographic Information System (GIS) tools, and then linked ramp operations data with applicable MOVES emission rates for the analyses.

This paper presents the data preparation in Section 2 and analytical methods in Section 3, respectively. Section 4 provides analytical results for on-road operations and emissions including presentation and discussion of: speed-acceleration plots, ramp emission rates based on the average speed, hotspot analysis, and road grade effects. Research results are useful for understanding transit bus operations and emission characteristics on various types of ramps, the potential impacts of ramp grade on emissions, and the ramp hotspot analysis. Finally, Section 5 concludes the research.

\section{Data Preparation}

To evaluate the emissions and fuel consumption of transit fleets, transit operations data were collected by GPS from 12 buses operating in the Detroit Metropolitan Area. The data included 381 bus-days between October 28th, 2014 and October 27th, 2015. At the time of data collection, the Detroit transit fleet included more than 500 transit buses (seating capacity of 33-42). About half of the fleet were compressed natural gas (CNG) buses, and the other half were diesel buses.

\subsection{Data Preprocessing}

Before emission analysis, collected GPS data need to go through the Kalman filter and spline process [17] to ensure their validity, accuracy, and continuity. GPS data quality varies with the GPS signal condition, characterized by the number of satellites and positional dilution of precision (PDOP) 
values. The modified discrete Kalman filter algorithm effectively controls GPS random errors. The Kalman gain matrix is generated using GPS quality criteria, including the quantity of satellites and the PDOP values. If the number of satellites is smaller than four and the PDOP is greater than eight, the quality of the speed is determined to be poor; therefore, the error variance in the matrix is high. The modified discrete Kalman filter algorithm was applied to the Detroit transit operation data to minimize the random errors from GPS loggers.

Another factor affecting the quality of GPS data is missing data. Missing segments exist in almost all of the GPS trip files due to obstruction and signal interference. If the missing data segments are of short duration, missing data can be reasonably interpolated from the speed profile. The research team used a cubic spline algorithm [18] to infill speed data when missing data segments were three seconds or less. Six good speeds points surrounding the missing data were required. Spline data consist of the three closest seconds before the start of the missing segment, all within 10 seconds before the missing segment, and the three closest seconds after the end of the missing segment, all within 10 seconds after the missing segment. If the good speeds could not be found within the 20 seconds surrounding the candidate segment, this segment was identified as missing and the splining process was abandoned. Missing segments longer than three seconds terminated the current drive trace (spitting the trace into two separate traces at that breakpoint).

After applying the Kalman filter and spline process, cycles less than 60 seconds in duration were discarded. The remaining 4717 vehicle-hours of transit bus operation were used to extract ramp operation data.

\subsection{ArcGIS-Based Ramp Data Extraction}

In this research, ArcGIS [19] analysis routines identify vehicle operations on-ramps. The shapefiles of the most recent Detroit road network were downloaded from Topologically Integrated Geographic Encoding and Referencing (TIGER) [4,20], and imported with the bus GPS data into ArcGIS. The roadway shapefiles indicate ramp locations, since the ramp acts as a transition between arterials and highways. To identify the road class shift, a $22 \mathrm{~m}$ buffer ( $3.66 \mathrm{~m}$ width/lane $\times 6$ lanes per direction) was created for each restricted-access highway centerline in each direction. To identify the physical rap boundaries, satellite images were overlaid on the ArcGIS base maps. Transit bus GPS data and roadway buffers identified the portions of the vehicle traces that were running on restricted highways, on the ramps, and on the local roads. The following boundary identification rules applied:

- Start of Freeway on-ramp

For diagonal ramp interchanges

For loop ramp interchanges

- End of Freeway on-ramp

For diagonal ramp interchanges

For loop ramp interchanges

- Start of Freeway off-ramp

For diagonal ramp interchanges

For loop ramp interchanges

- End of Freeway off-ramp

For diagonal ramp interchanges

For loop ramp interchanges

- Located at the free-flow connection with highway or local road 
For parallel-type ramp terminals, the ramp boundary was taken as the midpoint of the lane changing area (see Figure 1a))

For taper-type ramp terminals, the end of solid traffic line was taken as the ramp boundary (see Figure 1b))

- $\quad$ Ramp free-flow connection with local road

$\bigcirc \quad$ If no extension lanes applied, the edge of the access was taken as the boundary (see Figure 1c))

If extension lane applied, the midpoint of the lane changing area was taken as the boundary (see Figure 1d))

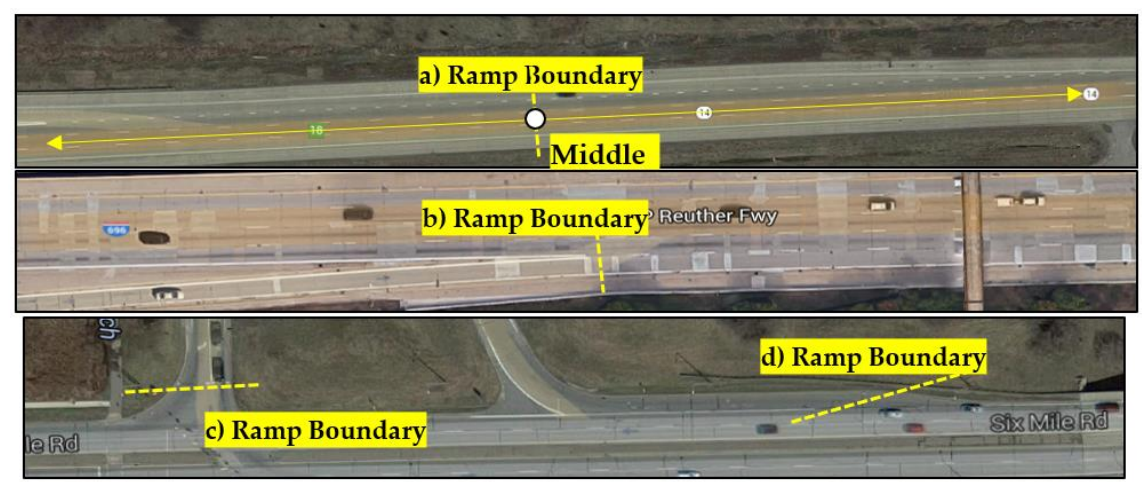

Figure 1. Ramp physical boundary.

A lot of manual labor was involved in establishing the ramp boundaries to ensure that GPS data were properly assigned to each ramp. Through this process, we also flagged points with ramp types. A total of 161 drive traces on-ramps were collected and analyzed (Table 1).

Table 1. Total of ramp cycles.

\begin{tabular}{|c|c|}
\hline \multicolumn{2}{|c|}{ Total of Ramp Cycles: 161} \\
\hline $\begin{array}{l}\text { On-ramp cycle: } 96 \\
\bullet \quad \text { Loop: } 35 \\
\text { - Diagonal: } 61\end{array}$ & $\begin{array}{c}\text { Off-ramp cycle: } 65 \\
\bullet \quad \text { Loop: } 15 \\
\bullet \quad \text { Diagonal: } 50\end{array}$ \\
\hline
\end{tabular}

Figure 2 shows the ramps layout covered by the transit GPS data and the transit bus in Metro Detroit.

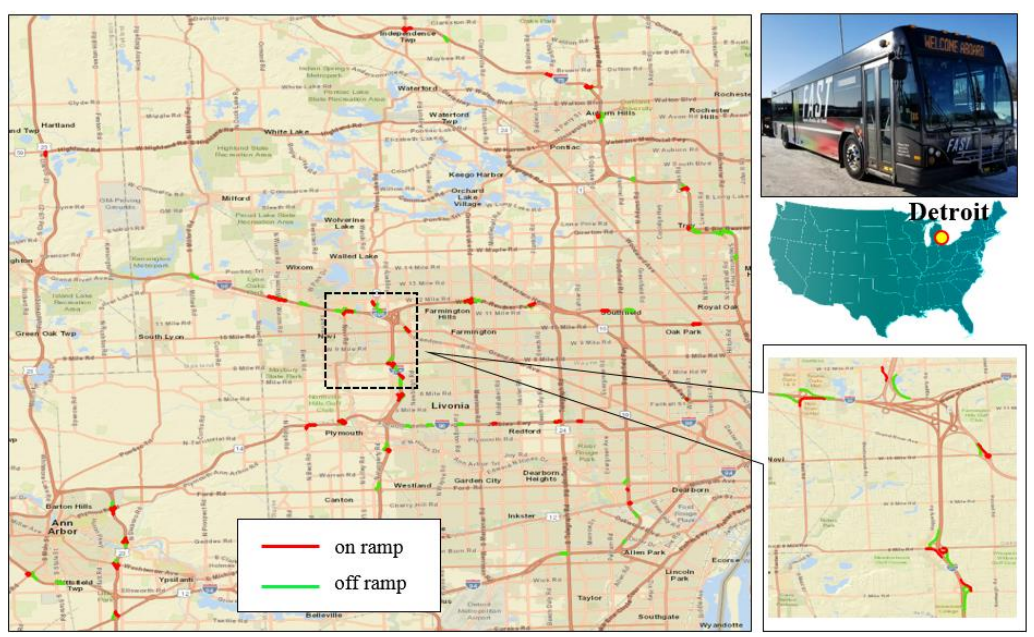

Figure 2. Ramp layout covered and the transit bus in the Metro Detroit. 


\section{Methodology}

\subsection{Ramp Cycle Determination or Ramp Effect Area}

After entering the highway from an on-ramp, the vehicle speed is normally lower than the design speed on the highway and the speed of traffic flow, forcing drivers to accelerate continuously and merge into the mainline traffic. In the same way, drivers tend to slow down when they leave the highway off-ramps. As such, highway operating speeds immediately after exiting on-ramps or before entering an off-ramp are likely to be affected by the presence of the ramps and the traffic volumes entering/exiting the freeway. For the analysis of emissions, including a portion of the highway as part of the ramp operations cycle is necessary, since high-speed and high-power operations may be associated with ramp effects. The ramp-associated driving traces were determined as follows:

- On-ramp cycle: speed trace within ramp plus the extension after the vehicle enters highway, i.e., post-ramp effect, in which vehicle accelerates continuously to the highway design speed;

- Off-ramp cycle: speed trace within off-ramp plus the extension of trace before the vehicles enter ramp (pre-ramp effect), in which vehicle decelerates beforehand to the ramp design speed;

Figure 3 presents two examples of speed traces assigned to the local road, ramp, and highway.

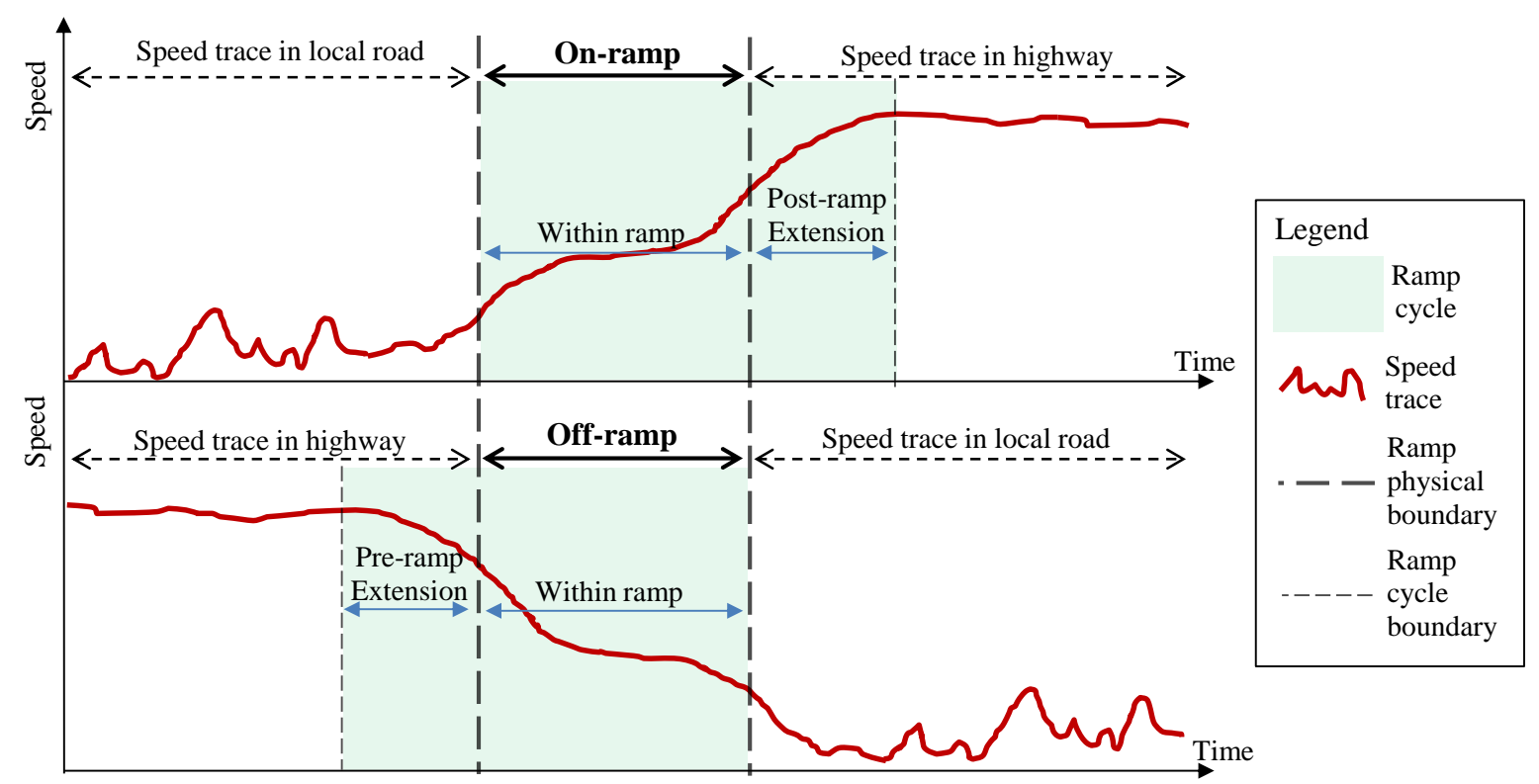

Figure 3. Examples of ramp-associated cycles and vehicle traces.

The duration of the extended cycle is dependent on factors such as an individual's driving behavior, ramp geometry, and traffic conditions. Based on the speed and acceleration characteristics, we created a method to determine the duration of the ramp cycle extension. A bracket was used to comprise five-consecutive second points on highways at the cycle right before or after the ramp boundary, and the speed/acceleration values of these five were judged. If the five points satisfied the criteria in Table 2, these points could be treated as part of the ramp cycle extension, and the bracket was moved forward by a one-second step at the post-ramp-associated trace (or backward for pre-ramp associated trace) and the same judgment was made. This process was carried out in a loop until points in bracket broke the criteria, where the midpoint (third point) will be regarded as the boundary of the ramp cycle. 
Table 2. Criteria for qualifying points as ramp cycle extension.

\begin{tabular}{|c|c|}
\hline Criteria & Reason \\
\hline \multicolumn{2}{|c|}{ a. Pre-ramp-effect area } \\
\hline I: Deceleration of 3 points $\leq-0.1 \mathrm{mph} / \mathrm{s}\left(0.0447 \mathrm{~m} / \mathrm{s}^{2}\right)$ & Most vehicles in deceleration mode \\
\hline $\begin{array}{l}\text { II: Speed decreases from } 1 \mathrm{st} \text { to } 5 \text { th point } \leq-1 \mathrm{mph} \\
\qquad\left(0.447 \mathrm{~m} / \mathrm{s}^{2}\right)\end{array}$ & Vehicle speed significantly decreases \\
\hline $\begin{array}{l}\text { III: For speed points within } 10 \mathrm{~s} \text { before the ramp, if } \\
\text { speed } \leq 50 \mathrm{mph}(80.47 \mathrm{~km} / \mathrm{h}) \text {, and within speed value } \\
\text { of the nearest point within ramp } \pm 3 \mathrm{mph}\left(1.341 \mathrm{~m} / \mathrm{s}^{2}\right)\end{array}$ & $\begin{array}{l}\text { Some vehicles decelerate to the desired ramp limit } \\
\text { speed before entering the off-ramp }\end{array}$ \\
\hline IV: Total effect duration $\leq 40 \mathrm{~s}$ & $\begin{array}{l}40 \mathrm{~s} \text { before entering off-ramp may not be considered } \\
\text { into the ramp-associated-effect area }\end{array}$ \\
\hline $\begin{array}{l}\text { V: Speed value at the middle of the } 5 \text { points } \leq 65 \mathrm{mph} \\
\qquad(104.61 \mathrm{~km} / \mathrm{h})\end{array}$ & $\begin{array}{l}\text { Speed approaching the highway speed limit is } \\
\text { considered }\end{array}$ \\
\hline Criteria implementation: & ((I and II) or III) and IV and V \\
\hline \multicolumn{2}{|c|}{ b. Post-ramp-effect area } \\
\hline I: Acceleration of 3 points $\geq+0.1 \mathrm{mph} / \mathrm{s}\left(0.0447 \mathrm{~m} / \mathrm{s}^{2}\right)$ & Most vehicles in acceleration mode \\
\hline $\begin{array}{l}\text { II: Speed increase from } 1 \mathrm{st} \text { to } 5 \text { th point } \geq+1 \mathrm{mph} \\
\qquad\left(0.447 \mathrm{~m} / \mathrm{s}^{2}\right)\end{array}$ & Vehicle speed significantly increases \\
\hline III: Total effect duration $\leq 40 \mathrm{~s}$ & $\begin{array}{c}40 \mathrm{~s} \text { after leaving on-ramp may not be considered into } \\
\text { the ramp-associated-effect area }\end{array}$ \\
\hline $\begin{array}{l}\text { IV: Speed value at the middle of the } 5 \text { points } \leq 65 \\
\qquad \mathrm{mph}(104.61 \mathrm{~km} / \mathrm{h})\end{array}$ & $\begin{array}{l}\text { Speed approaching the highway speed limit is } \\
\text { considered }\end{array}$ \\
\hline Criteria implementation: & I and II and III and IV \\
\hline
\end{tabular}

Figure 4 below presents the diagram of the bracket used to implement the algorithm and the movement along the speed trace. According to the ArcGIS process, the bold dashed lines are determined as the physical boundary of the ramp. Additionally, the light dashed line represents the boundary of the ramp operating trace. The algorithm is applicable to data obtained in this study. For other types of data sources, such as light-duty vehicles, the standard needs to be modified.

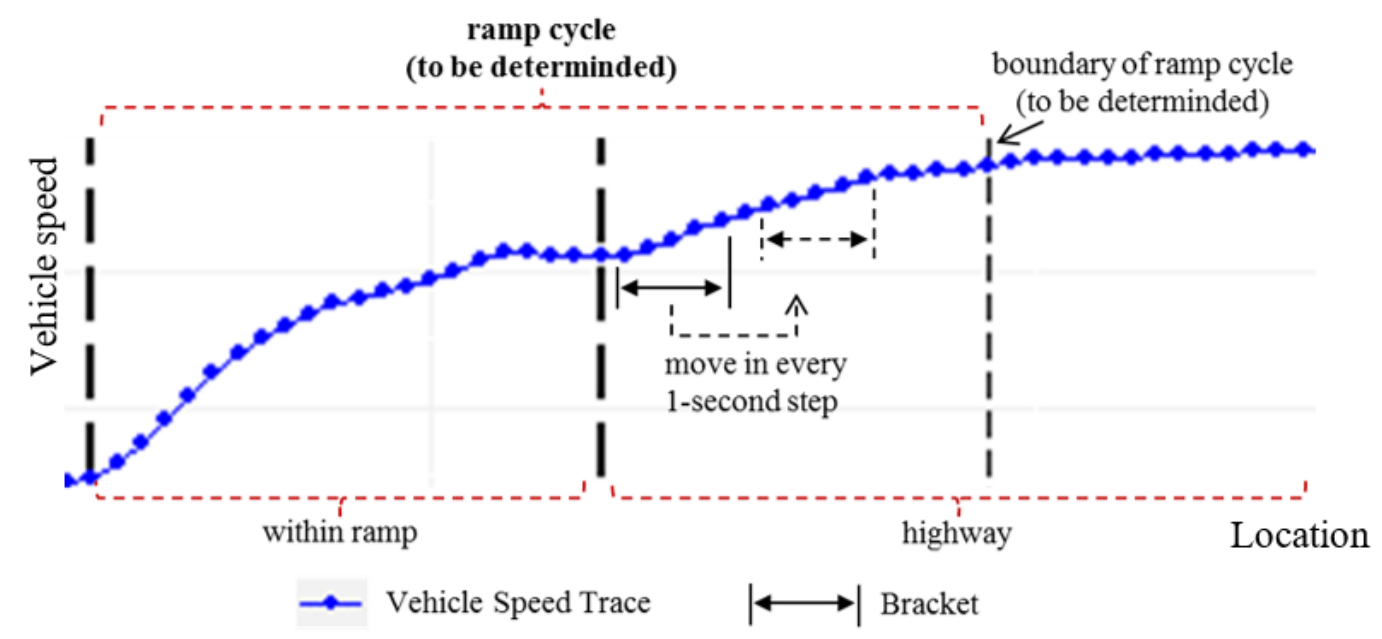

Figure 4. Cycle classification and bracket diagram.

After leaving a diagonal on-ramp, it took an average of $15.6 \mathrm{~s}$ of post-ramp extension (standard deviation of $13.3 \mathrm{~s}$ ) for bus drivers to reach the design speed of the highway. By contrast, it took longer for a post-ramp extension (an average value of $24.5 \mathrm{~s}$ and a standard deviation of $14.1 \mathrm{~s}$ ) to approach the design speed after leaving a loop on-ramp. The reason is drivers tried to keep a lower speed 
when driving through a loop ramp, and a longer post-acceleration time was required. The pre-ramp extension of a diagonal off-ramp cycle was just $2.9 \mathrm{~s}$ on average, and the extension of a loop off-ramp was $6.5 \mathrm{~s}$.

\subsection{STP Calculation and Operating Mode Bin Generation}

In this research, emissions were determined through emission inventory from MOVES 2014. For each second, scaled tractive power (STP) and an operating mode bin as defined in MOVES needed to be generated as a bridge between bus activity and emission inventory [1]. The second-by-second STP formulation is expressed as:

$$
S T P=\frac{A v+B v^{2}+C v^{3}+M v(a+g \sin \theta)}{f_{\text {scale }}}
$$

where

A: the tire rolling resistance coefficient (kilowatt second)/(meter)

B: the mechanical rotating friction coefficient (kilowatt second $\left.{ }^{2}\right) /\left(\right.$ meter $\left.^{2}\right)$

C: the aerodynamic drag coefficient (kilowatt second $\left.{ }^{3}\right) /\left(\right.$ meter $\left.^{3}\right)$

M: the source type in metric tons (metric tons)

$f_{\text {scale }}$ : scaling factor for heavy-duty vehicles

$\mathrm{v}$ : the speed of the vehicle $(\mathrm{m} / \mathrm{s})$

a: the vehicle acceleration $\left(\mathrm{m} / \mathrm{s}^{2}\right)$

$\sin \theta$ : the road grade (percent)

$\mathrm{g}$ : the acceleration rate due to gravity $\left(9.8 \mathrm{~m} / \mathrm{s}^{2}\right)$

Detroit transit bus models correspond to transit bus (source use type ID $=42$ ) in the MOVES model, so $\mathrm{A}, \mathrm{B}, \mathrm{C}, \mathrm{M}$, and $f_{\text {scale }}$ were determined as $1.03968,0,0.00358702,16.556$, and 17.1 , respectively from the MOVES database sourceusetypephysics. The second-by-second operating mode bin was generated by STP, speed, and acceleration value. The criteria of each operating mode bin were summarized in [20], as well as in Table 3. Most of the results in this research were obtained by assuming a flat gradient $(\sin \theta=0)$, considering the terrain in Detroit is relatively flat. These results can be regarded as the benchmark and the ramp grade effects will be specifically investigated in the last section as a sensitivity analysis.

\subsection{Emission Rates Assignment}

Emissions results were based on MOVES emission rates with real-world speed trace and GPS speed data. We obtained second-by-second emissions for each ramp cycle as the fundamental data set for the statistical analysis. As the sample size (the number of ramp cycles) becomes larger, which in this case was 161, it would take much time in input preparation and running MOVES. In addition, a lot of replicated calculations would be needed in the sensitivity analysis of the ramp gradient effect, and running MOVES is neither convenient nor economical for multi-scenarios with only one parameter (grade) changed.

Instead of running ramp cycle in county-level MOVES, we ran MOVES 2014 in project-level to get the emission rates for bus applied with national default age distribution [21], and obtain the emission rates in $\mathrm{g} / \mathrm{h}$ for each operating mode bin of the fleet. Here is the scenario we set to get the emission rates from MOVES:

- $\quad$ Month and Year: July 2019

- Date and Time: weekday, 5:00-6:00 p.m.

- Region: Detroit

- Meteorology (default value): 
- Temperature: $85.6^{\circ} \mathrm{F}\left(27.8^{\circ} \mathrm{C}\right)$

- Humidity: $50.3 \%$

- Fuel: default value from MOVES 2014

- Inspection/Maintenance (I/M) Strategy: default 2019 I/M strategy from MOVES

- $\quad$ Source Type: transit bus (source type ID = 42)

- Age Distribution: 2019 national default values

- 23 Links: each link was applied with $100 \%$ fraction of one operating mode bin, and the time was scaled to 1-hour operation using the link length and link average speed

Table 3. Motor Vehicle Emissions Simulator (MOVES) scaled tractive power (STP) operating mode bins.

\begin{tabular}{|c|c|c|c|c|}
\hline Operating Mode & Operating Mode & STP & Vehicle Speed & Vehicle Acceleration \\
\hline ID & Description & (KW/tonne) & $\left(v_{t}, \mathrm{mph}\right) *$ & $(\mathrm{a}, \mathrm{mph} / \mathrm{s}) *$ \\
\hline 0 & Deceleration/Braking & & & $\begin{array}{c}\mathrm{a}_{\mathrm{t}} \leq-2.0 \text { OR }\left(\mathrm{a}_{\mathrm{t}}<-1.0\right. \\
\text { AND } \mathrm{a}_{\mathrm{t}-1}<-1.0 \text { AND } \\
\left.\mathrm{a}_{\mathrm{t}-2}<-1.0\right)\end{array}$ \\
\hline 1 & Idle & & $-1 \leq \mathrm{v}_{\mathrm{t}}<1$ & Any \\
\hline 11 & Coast & $\mathrm{STP}_{\mathrm{t}}<0$ & $0 \leq \mathrm{v}_{\mathrm{t}}<25$ & Any \\
\hline 12 & Cruise/Acceleration & $0 \leq \mathrm{STP}_{\mathrm{t}}<3$ & $0 \leq \mathrm{v}_{\mathrm{t}}<25$ & Any \\
\hline 13 & Cruise/Acceleration & $3 \leq \mathrm{STP}_{\mathrm{t}}<6$ & $0 \leq \mathrm{v}_{\mathrm{t}}<25$ & Any \\
\hline 14 & Cruise/Acceleration & $6 \leq \mathrm{STP}_{\mathrm{t}}<9$ & $0 \leq \mathrm{v}_{\mathrm{t}}<25$ & Any \\
\hline 15 & Cruise/Acceleration & $9 \leq \mathrm{STP}_{\mathrm{t}}<12$ & $0 \leq \mathrm{v}_{\mathrm{t}}<25$ & Any \\
\hline 16 & Cruise/Acceleration & $12 \leq \mathrm{STP}_{\mathrm{t}}$ & $0 \leq \mathrm{v}_{\mathrm{t}}<25$ & Any \\
\hline 21 & Coast & $\mathrm{STP}_{\mathrm{t}}<0$ & $25 \leq \mathrm{v}_{\mathrm{t}}<50$ & Any \\
\hline 22 & Cruise/Acceleration & $0 \leq \mathrm{STP}_{\mathrm{t}}<3$ & $25 \leq \mathrm{v}_{\mathrm{t}}<50$ & Any \\
\hline 23 & Cruise/Acceleration & $3 \leq \mathrm{STP}_{\mathrm{t}}<6$ & $25 \leq \mathrm{v}_{\mathrm{t}}<50$ & Any \\
\hline 24 & Cruise/Acceleration & $6 \leq \mathrm{STP}_{\mathrm{t}}<9$ & $25 \leq \mathrm{v}_{\mathrm{t}}<50$ & Any \\
\hline 25 & Cruise/Acceleration & $9 \leq \mathrm{STP}_{\mathrm{t}}<12$ & $25 \leq \mathrm{v}_{\mathrm{t}}<50$ & Any \\
\hline 27 & Cruise/Acceleration & $12 \leq \mathrm{STP}_{\mathrm{t}}<18$ & $25 \leq \mathrm{v}_{\mathrm{t}}<50$ & Any \\
\hline 28 & Cruise/Acceleration & $18 \leq \mathrm{STP}_{\mathrm{t}}<24$ & $25 \leq \mathrm{v}_{\mathrm{t}}<50$ & Any \\
\hline 29 & Cruise/Acceleration & $24 \leq \mathrm{STP}_{\mathrm{t}}<30$ & $25 \leq \mathrm{v}_{\mathrm{t}}<50$ & Any \\
\hline 30 & Cruise/Acceleration & $30 \leq \mathrm{STP}_{\mathrm{t}}$ & $25 \leq \mathrm{v}_{\mathrm{t}}<50$ & Any \\
\hline 33 & Cruise/Acceleration & $\mathrm{STP}_{\mathrm{t}}<6$ & $50 \leq \mathrm{v}_{\mathrm{t}}$ & Any \\
\hline 35 & Cruise/Acceleration & $6 \leq \mathrm{STP}_{\mathrm{t}}<12$ & $50 \leq \mathrm{v}_{\mathrm{t}}$ & Any \\
\hline 37 & Cruise/Acceleration & $12 \leq \mathrm{STP}_{\mathrm{t}}<18$ & $50 \leq v_{t}$ & Any \\
\hline 38 & Cruise/Acceleration & $18 \leq \mathrm{STP}_{\mathrm{t}}<24$ & $50 \leq v_{t}$ & Any \\
\hline 39 & Cruise/Acceleration & $24 \leq \mathrm{STP}_{\mathrm{t}}<30$ & $50 \leq \mathrm{v}_{\mathrm{t}}$ & Any \\
\hline 40 & Cruise/Acceleration & $30 \leq \mathrm{STP}_{\mathrm{t}}$ & $50 \leq v_{t}$ & Any \\
\hline
\end{tabular}

The emission rate was assigned to each second from the matrix table of bus emission rate, based on the operating mode bin of each second. For example, the $\mathrm{CO}$ emission rate of a bus per second with operating mode bin ID as $15(9 \mathrm{~kW} /$ metric ton $\leq \mathrm{STP}<12 \mathrm{~kW} /$ metric ton, $1 \mathrm{mph} \leq$ speed $<25 \mathrm{mph}$, or $1.61 \mathrm{~km} / \mathrm{h} \leq$ speed $<40.23 \mathrm{~km} / \mathrm{h}$ ) was assigned as the CO emission factor $447.698 \mathrm{~g} / \mathrm{h}$ for operating mode bin 15 from look-up table, i.e., emission rate as $184.84(\mathrm{~g} / \mathrm{h}) \div 3600$ (second/hour) $=0.124 \mathrm{~g} / \mathrm{s}$. This process was more efficient than directly running MOVES since it saved time in duplicated calculations. 
Moreover, it has been validated that the aggregated emission results from second-by-second emission rates are the same as running the MOVES model. We accomplished the emission assignment through Java and its connection with MySQL [22].

Five criteria pollutant emissions ( $\mathrm{HC}, \mathrm{CO}, \mathrm{NO}_{\mathrm{X}}, \mathrm{PM}_{10}$, and $\left.\mathrm{PM}_{2.5}\right)$, greenhouse gases (GHGs), and fuel consumption rate were estimated. GHGs is quantified as $\mathrm{CO}_{2} \mathrm{e}$, or carbon dioxide equivalent, a measure to compare the emissions from three greenhouse gases based on their global warming potential from vehicle sources using $\mathrm{CO}_{2}$ as the reference over 100 years. For example, the global warming potential for methane over 100 years is 21 . This means that emissions of one million metric tons of methane is equivalent to emissions of 21 million metric tons of carbon dioxide. Based on MOVES calculation, $\mathrm{PM}_{10}$ is linearly related to $\mathrm{PM}_{2.5}$, and fuel and $\mathrm{CO}_{2} \mathrm{e}$ are linearly related to $\mathrm{CO}_{2}$. It is known that the majority of $\mathrm{HC}$ emissions come from a cold start and evaporations instead of from the running mode. The result analysis in this research mainly focused on $\mathrm{CO}, \mathrm{NO}_{\mathrm{X}}, \mathrm{PM}_{2.5}$, and $\mathrm{CO}_{2}$.

From the second-by-second data, we aggregated operations and emissions by ramp cycle, by ramp functions, and by roadway segments. Furthermore, the speed trace and aligned emission rates can help to understand the emission factor of the ramp cycle in different segments, which is useful for the hotspot analysis.

\section{Results and Discussion}

\subsection{Speed-Acceleration Plots}

Figure 5 shows the speed-acceleration results from on-ramp cycles and off-ramp cycles, where points from within ramps and extension areas are flagged with different colors.
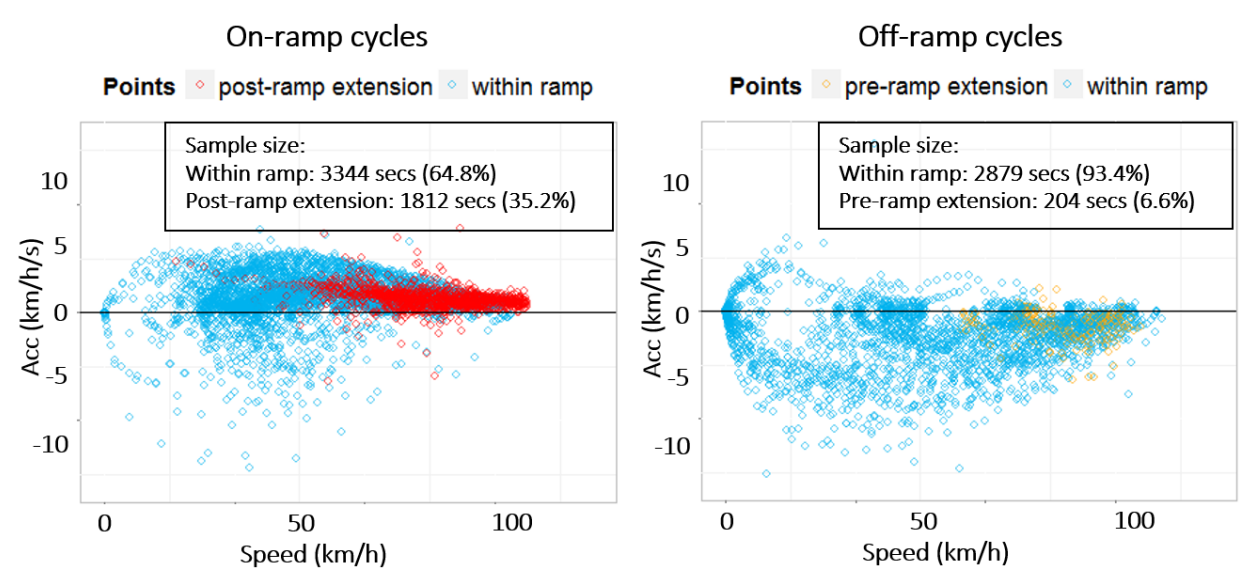

Figure 5. Speed-acceleration from on-ramp and off-ramp cycles.

For on-ramp cycles, $87 \%$ of points were classified as in acceleration mode, $35.2 \%$ of on-ramp cycle points were contributed from extension areas that defined where vehicles continue to accelerate right after entering highways to reach the desired highway speed. Points in extension areas (red points) were in high-speed level ( $\geq 64.37 \mathrm{~km} / \mathrm{h}$ or $40 \mathrm{mph}$ ) and acceleration mode, in which vehicles tend to generate high emissions, and this will be reflected in the aggregated emission results and hotspot analysis.

For cycles in off-ramp, $78.8 \%$ of points were in deceleration mode (see Figure 5). Only $6.6 \%$ of off-ramp cycle points resulted from pre-ramp extension (yellow points) defined as where drivers decelerate right before entering ramps to adjust from the highway speed to the desired ramp speeds. Emissions from off-ramp cycles are expected to be relatively low compared with cycles from other road types or ramps.

\subsection{Emission Rates Based on the Average Speed}

Emission rates in $\mathrm{g} / \mathrm{km} /$ vehicle by ramp cycle were calculated by summing up the second-by-second emissions and dividing by distance. In Figure 6, the scatterplots indicate the average speed and 
emission rates $(\mathrm{g} / \mathrm{km})$ on the ramp cycle for $\mathrm{CO}, \mathrm{PM}_{2.5}, \mathrm{NO}_{X}$, and $\mathrm{CO}_{2}$, flagged with different colors for on-ramp and off-ramp, and with Locally Estimated Scatterplot Smoothing (LOESS) applied [23], or local polynomial regression, to represent the overall trends of speed-emission rates. The emission rate of the same bus fleet under MOVES highway and local cycles was also calculated and shown below as black and blue curves. From the comparison, at the same speed level higher than $64.37 \mathrm{~km} / \mathrm{h}$ or $40 \mathrm{mph}$, since a lot of acceleration modes involved in on-ramps, emission rates for the on-ramp cycle were approximately twice higher than emission rates from MOVES highway cycles. Moreover, on-ramp emissions were diverse under the same speed level, indicating unknown factors that need to be examined further in detailed on-ramp emission modeling, in which factor might be individual behaviors, ramp configuration, traffic condition, etc. At the low-speed level ( $<64.37 \mathrm{~km} / \mathrm{h}$ or $40 \mathrm{mph})$, as the average speed decreased, on-ramp emission rates decreased to approaching the highway emission rates, and this was due to the lower fraction of aggressive accelerations involved. Off-ramp emission rates were almost half of the highway emissions since a lot of deceleration modes were involved.

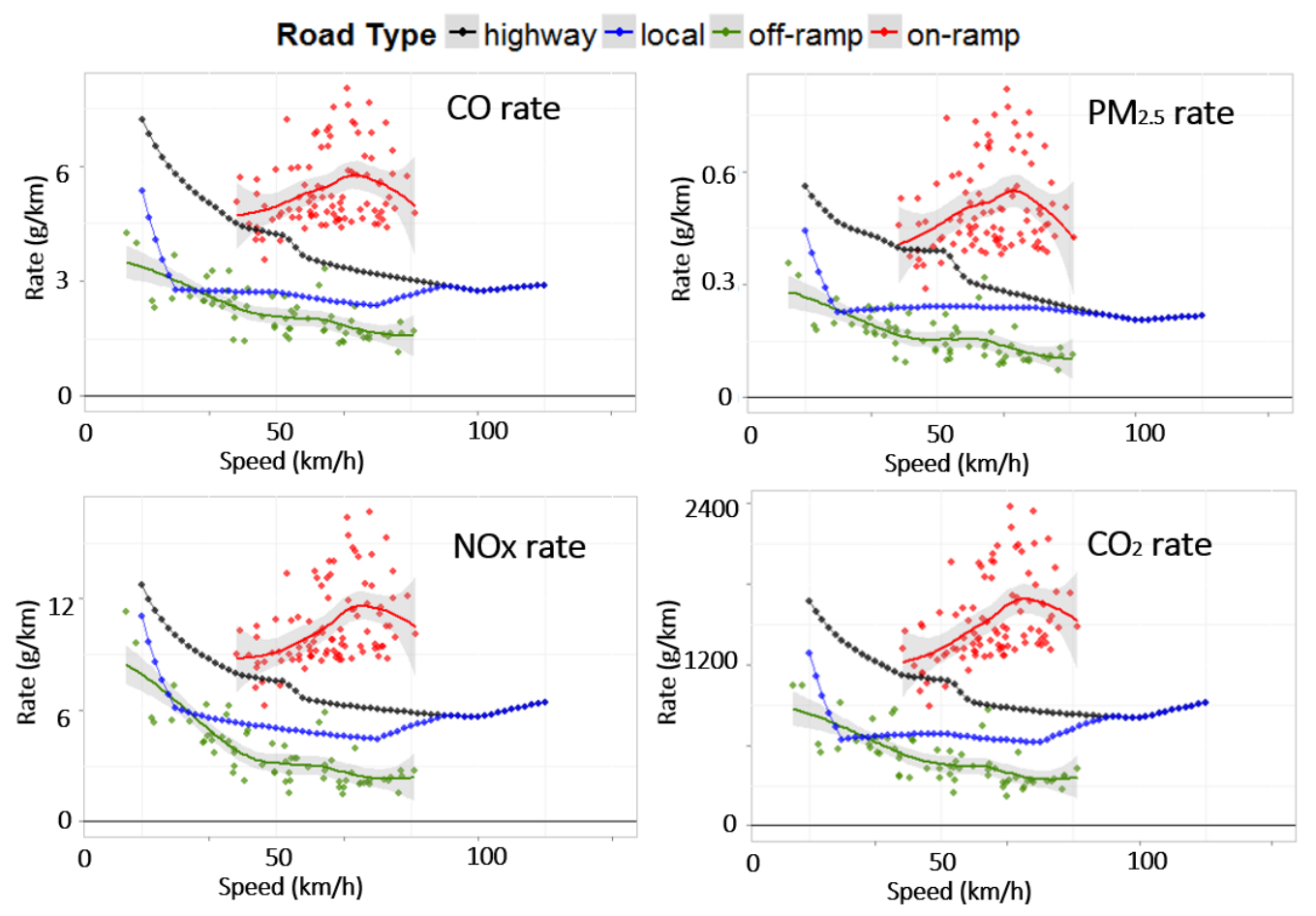

Figure 6. Bus emission rates $(\mathrm{g} / \mathrm{km})$ under ramp cycles and MOVES highway/local default cycles.

\subsection{Hotspot Analysis}

Since transit buses produce a lot of emissions when operating on the on-ramp cycle, second-by-second speed $(\mathrm{km} / \mathrm{h})$, second-by-second emissions $(\mathrm{g} / \mathrm{s})$, and emission rates $(\mathrm{g} / \mathrm{km})$ by sub-cycle segment (i.e., within ramp, post-extension, and highway) of on-ramp cycle were presented to explore the significance of a potential hotspot.

Figure 7 provides an example of hotspot analysis by illustrating the second-by-second speed and MOVES-based $\mathrm{CO}$ and $\mathrm{PM}_{2.5}$ emission rates for a transit bus driving through a diagonal on-ramp and a loop on-ramp. It should be noted that acceleration is the main operation mode that contributes to on-road emissions, which mainly happened on the on-ramps. There were not much emissions coming from off-ramps, since the operation modes during off-ramps are mainly braking and deceleration. Therefore, we only present the on-ramp results. Based on the MOVES estimation, a lot of emissions were produced within a diagonal on-ramp. By contrast, for a loop on-ramp, lots of emissions were generated in the post-ramp extension area. This is because drivers generally keep a comparatively stable and low speed as they go through the loop ramp, and then are compelled to accelerate to the 
highway design speed after entering the highway, resulting in highway emissions in the extension area. This indicated the importance of involving the extension area into the ramp operation hotspot analysis. The results shown in Figure 7 are clear to help us identify the hotspots of emissions.

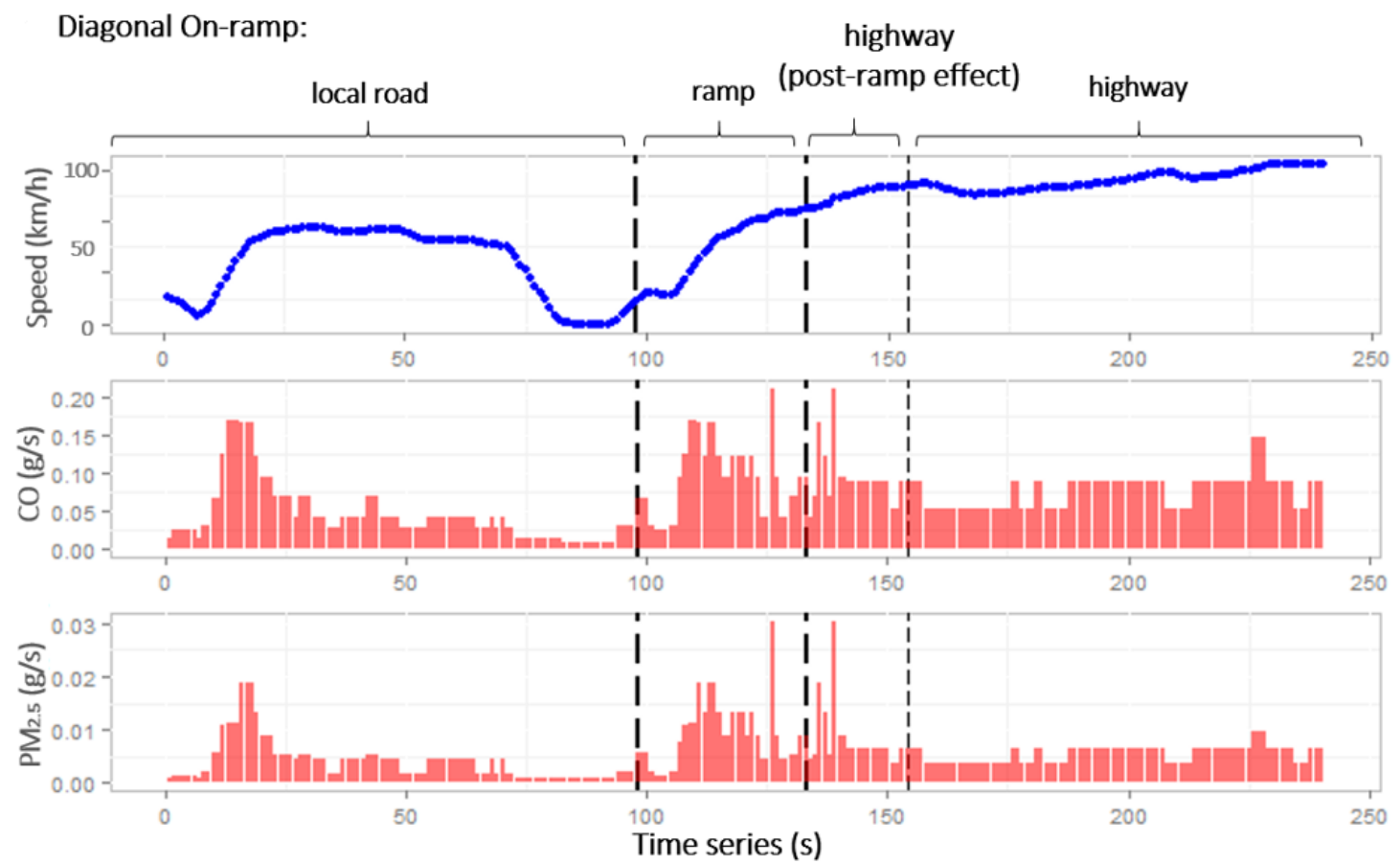

(a)

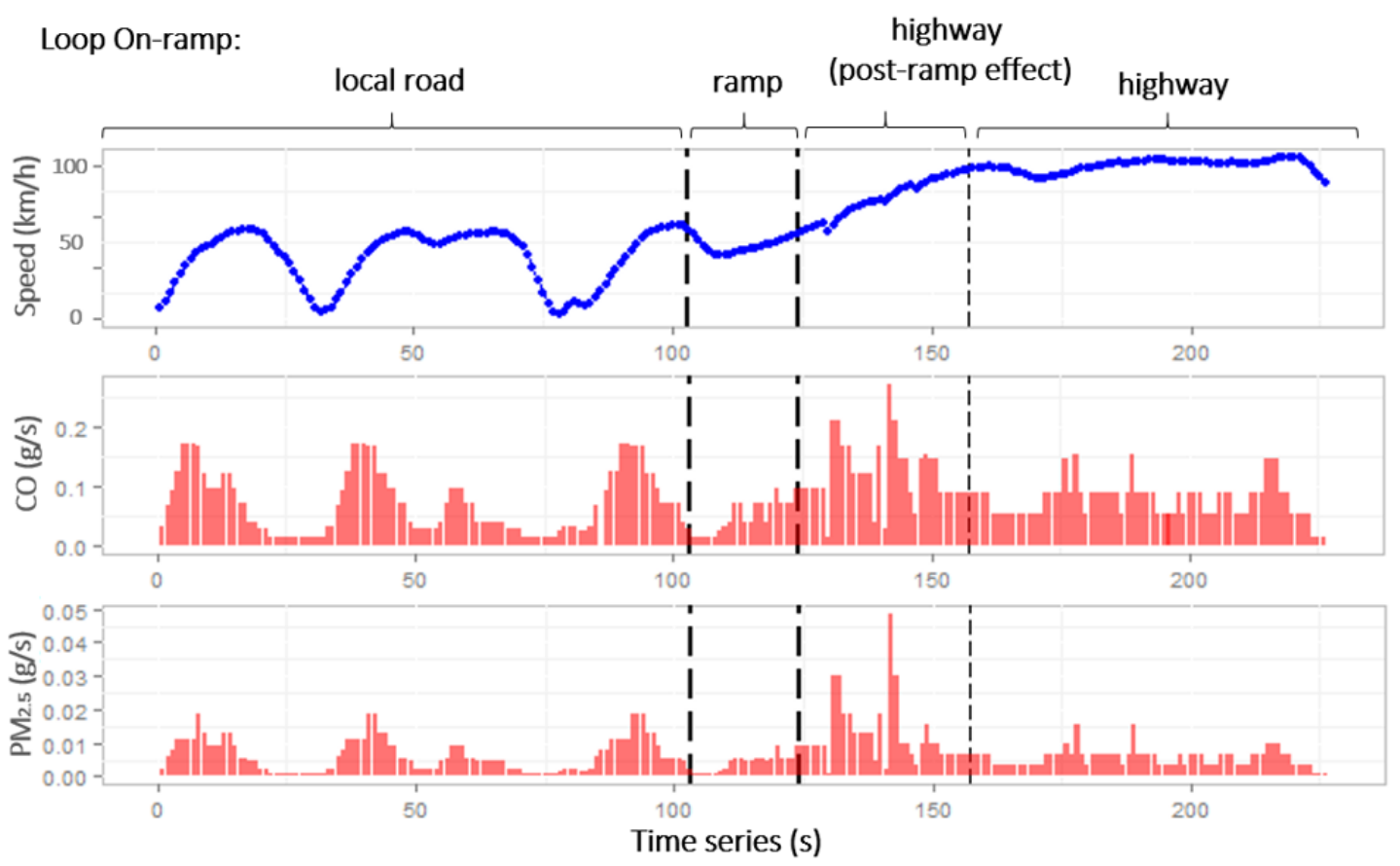

(b)

Figure 7. Second-by-second speed, $\mathrm{CO}$, and Particulate Matter $2.5\left(\mathrm{PM}_{2.5}\right)$ rate $(\mathrm{g} / \mathrm{s})$ of bus under on-ramp cycle; (a) diagonal on-ramp; (b) loop on-ramp. 
Within each on-ramp cycle, $\mathrm{CO}$ and $\mathrm{PM}_{2.5}$ emission rates were measured for each sub-cycle segment, i.e., within the ramp, by post-ramp extension, and connected highway, based on real-world operations. The emission rates of all 96 on-ramp cycles were aggregated into the average values as shown in Figure 8 below, and the standard deviation was flagged on top of each bar chart.
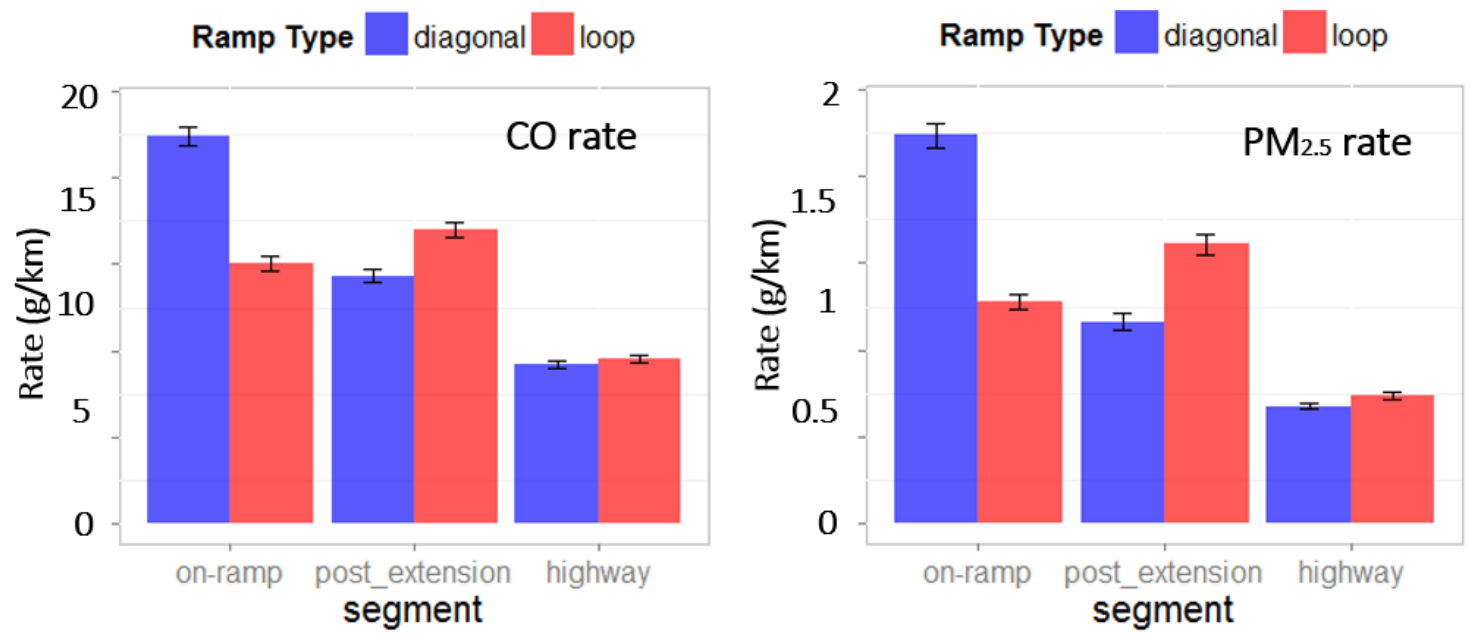

Figure 8. On-ramp $\mathrm{CO}$ and $\mathrm{PM}_{2.5}$ rate $(\mathrm{g} / \mathrm{km})$ by sub-cycle segment.

In general, for diagonal on-ramps, emission rates of transit buses reached a peak within the on-ramp area. While for loop on-ramps, emission rates of transit buses in the post-ramp extension area reached the peak. Emission rates of transit buses ramp sub-cycle within both ramp area and post-ramp extension (in the highway) were higher than those of vehicles in highway operations. This indicated that for the emission analysis of on-ramps, besides on-ramp segments, emission rate in a certain extension area on connected highways could also be high, particularly for the loop on-ramp. Therefore, we should include post-extension areas as well as on-ramps while conducting the hotspot analysis.

\subsection{Sensitivity Analysis of the Ramp Grade}

All previous results were based on the assumption of flat terrain with road grade set at zero, it needs to be noticed that road gradient is indeed a factor that could significantly affect emission results and is especially likely to contribute to emissions on-ramp, since the connected local road and highway tend to be at different elevations. However, it is not easy to obtain robust altitudinal data or road slope data. Therefore, this research conducted a sensitivity analysis. By doing this, road grades in the ramps were set from $-6 \%$ to $+6 \%$, with $1 \%$ interval, which covered most cases, since ramp grade is required to be within $\pm 5 \%$, and preferred within $\pm 4 \%$ [16]. Emission rates in $\mathrm{g} / \mathrm{km} / \mathrm{vehicle}$ of each ramp cycle in each grade scenario were calculated based on the same method. Grades of post-ramp sub-cycle were still set at zero since the connected highway and local road were assumed to be relatively flat.

Emissions from "flat" ramp cycle (grade $=0 \%$ ) were regarded as reference values. Ramp grade effect could be reflected by comparing emission rate changes of all scenarios with the "flat" scenario. The emission change is expressed as:

$$
\text { Emission Change }=\frac{\text { EmRate }_{x \%}-\text { EmRate }_{0} \%}{\text { EmRate }_{0} \%} \times 100 \%
$$

where

EmRate $_{\mathrm{x} \%}$ : the emission rate $(\mathrm{g} / \mathrm{km})$ of ramp cycle with $\mathrm{x} \%$ ramp grade applied $(-6 \%-+6 \%)$ EmRate $_{0 \%}$ : the emission rate $(\mathrm{g} / \mathrm{km})$ of ramp cycle with $0 \%$ ramp grade applied

Figure 9 below presents the average emission changes in the on-ramp cycle and off-ramp cycle under different ramp grade values. A significant contribution of emissions could be due to the effect 
of road grades: for example, when the road grade changed from $0 \%$ to $+4 \%$, the overall $\mathrm{CO}, \mathrm{NO}_{\mathrm{X}}$, and $\mathrm{CO}_{2}$ emission rate of transit driving through upward on-ramp could be increased by $35-45 \%$, and the $\mathrm{PM}_{2.5}$ rate could be increased by as much as $50 \%$. The estimated emissions grow linearly with the grade, which might be due to the capped operating mode bin in MOVES that restricts further emissions estimation on extremely high engine load. Real-world data are required to better describe the impact of road grade.

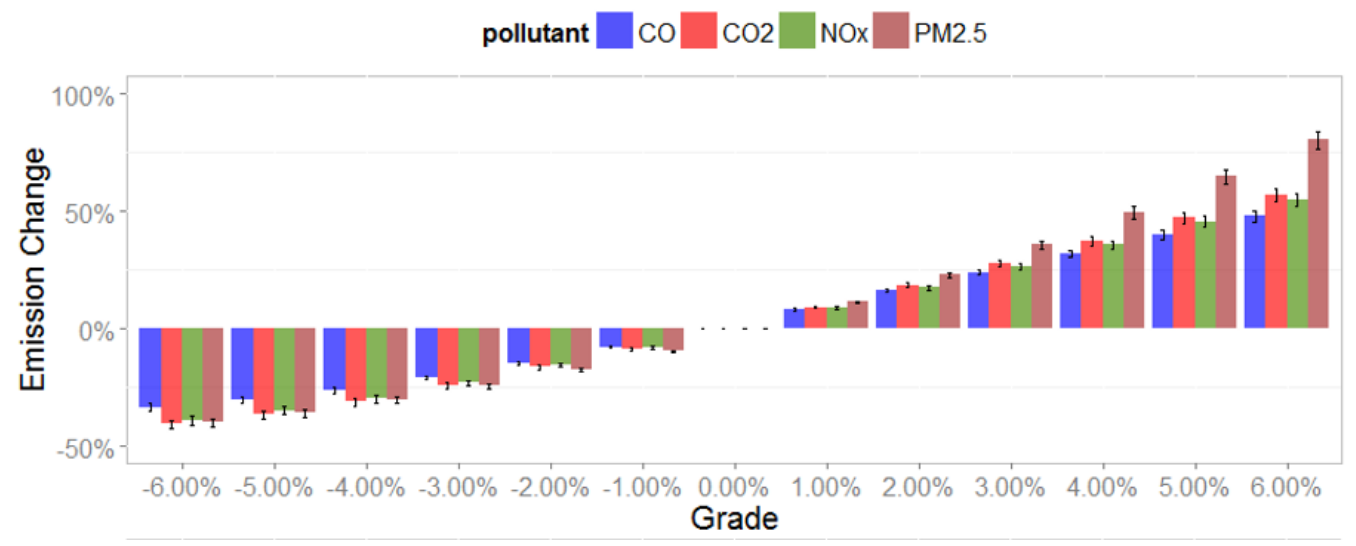

(a)

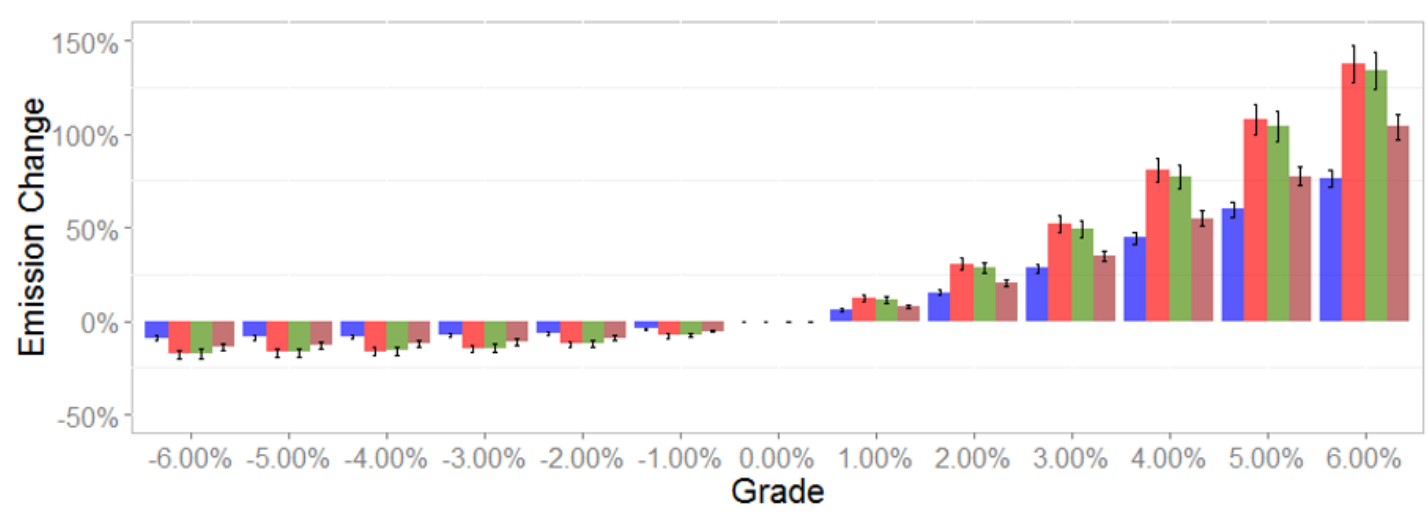

(b)

Figure 9. Emission changes from ramp grade effect; (a) On-ramp effect; (b) Off-ramp effect.

\section{Conclusions}

This research presented operations and emission characteristics of transit buses driving through ramps. Second-by-second speed and position data were collected in 2015 from the Detroit transit system, the principal rapid transit system in Detroit. Ramp-associated operations were extracted from daily trips and assigned with emission rates from MOVES 2014. Some key findings are summarized below:

1. In ramp operation and emission analysis, it is significant to consider not only bus behaviors within the ramp, but also pre-ramp decelerations before buses entering the off-ramps from the highway, and post-ramp accelerations after vehicle enter the highway from the on-ramps, where vehicle operations are different from operations of the mainstream highway traffic.

2. In this research, based on the transit bus, on loop on-ramp operations, $\mathrm{CO}$ and $\mathrm{PM}_{2.5}$ rate of the bus during post-ramp operations are even greater than operations within ramps, with the presumption of zero road grade, which indicates it is necessary to treat the post-ramp area separately from the highway links in the hotspot analysis.

3. At a speed level of higher than $40 \mathrm{mph}(64.37 \mathrm{~km} / \mathrm{h})$, emission rates of transit buses under on-ramp operations are about twice higher than emission rates from the MOVES highway cycles. At the 
low-speed level ( $<40 \mathrm{mph}$ or $64.37 \mathrm{~km} / \mathrm{h}$ ), as the average speed decreased, on-ramp emission rates reduced to approach the highway emission rates due to the lower fraction of aggressive accelerations involved. Off-ramp emission rates are almost half of the highway emissions. On-ramp emissions are varying, indicating unknown factors that need further research in detailed on-ramp emission modeling.

4. The sensitivity analysis of the ramp grade indicated that, for project-level analysis, ramp grade is an unavoidable factor. When ramp grade changed from $0 \%$ to $+4 \%$, the overall $\mathrm{CO}, \mathrm{NO}_{X}$, and $\mathrm{CO}_{2}$ emission rates of transit buses driving through upward on-ramp could be increased by $35-45 \%$, and the $\mathrm{PM}_{2.5}$ rate could be increased by as much as $50 \%$.

This study focused on heavy-duty buses. Although the bus emissions are significantly higher than those of light-duty vehicles, the results show similar trends with MOVES-based study on the light-duty vehicle emissions [4]. The on-ramp emission rates at on-ramps are 1.5-2 times larger than freeway emissions, depending on the average speed, which is consistent with the real-world based study conducted by [10].

This research was useful for presenting driving characteristics and emissions of transit buses on different types of ramps. It is a further step for ramp classification, investigating the influence of ramp gradient, and the development of the ramp cycle for emission modeling. Some suggestions were provided in terms of implementing hotspot analysis for the on-ramps. While only transit data were applied in this study, the method can be extended to the heavy-duty trucks or the light-duty vehicles.

Author Contributions: Conceptualization, H.L. and S.Z.; methodology, H.L. and S.Z.; software, H.L.; validation, H.L. and G.C.; formal analysis, H.L.; investigation, H.L.; resources, H.L. and S.Z.; data curation, H.L. and Q.G.; writing-original draft preparation, H.L.; writing_-review and editing, S.Z., G.C., and Q.G.; visualization, H.L.; supervision, S.Z.; project administration, G.C.; funding acquisition, S.Z. and G.C. All authors have read and agreed to the published version of the manuscript.

Funding: This research was funded by the Fundamental Research Funds for the Central Universities (grant no. 2017IVA010, 2018IVB070) and the National Natural Science Foundation of China (no. 71701159).

Conflicts of Interest: The authors declare no conflict of interest.

\section{References}

1. USEPA. Population and Activity of On-road Vehicles in MOVES2014. EPA-420-R-16-003a. 2016. Available online: https://nepis.epa.gov/Exe/ZyPDF.cgi?Dockey=P100O7PS.pdf (accessed on 31 March 2020).

2. USEPA. Development of Methodology for Estimating VMT Weighting by Facility Type. EPA420-R-01-009. Systems Applications International, Inc. April 2001. Available online: http://www.epa.gov/OMS/models/ mobile6/r01009.pdf (accessed on 31 March 2020).

3. USEPA. Transportation Conformity Guidance for Quantitative Hot-spot Analyses in PM2.5 and PM10 Nonattainment and Maintenance Areas. EPA-420-B-10-040. Available online: http://www.epa.gov/otaq/ stateresources/transconf/policy/420b10040-appx.pdf (accessed on 31 March 2020).

4. Liu, H.; Sonntag, D.; Brzezinski, D.; Fulper, C.R.; Hawkins, D.; Warila, J.E. Operations and Emissions Characteristics of Light-Duty Vehicles on Ramps. Transp. Res. Record J. Transp. Res. Board 2016, 2570, 1-11. [CrossRef]

5. Liu, H.; Stockwell, N.; Rodgers, M.O.; Guensler, R. A comparative life-cycle energy and emissions analysis for intercity passenger transportation in the US by aviation, intercity bus, and automobile. Transp. Res. Part D Transp. Environ. 2016, 48, 267-283. [CrossRef]

6. Thornton, M.; Dixon, K.; Guensler, R. Emissions Impact of Ramp Metering Strategies on the Atlanta Freeway System. Cooperating Research Council, On-road Vehicle Emission Workshop. 26-29 March 2000, San Diego, CA. Available online: http://transaq.ce.gatech.edu/guensler/publications/others/CRC00thornton.pdf (accessed on 31 March 2020).

7. Bae, S.-H.; Heo, T.-Y.; Ryu, B.-Y. An evaluation of the ramp metering effectiveness in reducing carbon dioxide emissions. Simulation 2012, 88, 1368-1378. [CrossRef]

8. Du, J.; Li, Q.; Qiao, F. Impact of Different Ramp Metering Strategies on Vehicle Emissions Along Freeway Segments. J. Transp. Health 2018, 9, S51. [CrossRef] 
9. Du, J.; Li, Q.; Qiao, F.; Yu, L. Estimation of Vehicle Emission on Mainline Freeway Under Isolated And Integrated Ramp Metering Strategies. Environ. Eng. Manag. J. (EEMJ) 2018, 17, 1237-1248. [CrossRef]

10. Frey, H.C.; Delavarrafiee, M.; Singh, S. Real-World Freeway and Ramp Activity and Emissions for Light-Duty Gasoline Vehicles. Transp. Res. Record J. Transp. Res. Board 2017, 2627, 17-25. [CrossRef]

11. Frey, H.C.; Rouphail, N.M.; Zhai, H. Speed-and facility-specific emission estimates for on-road light-duty vehicles on the basis of real-world speed profiles. Transp. Res. Rec. 2006, 1987, 128-137. [CrossRef]

12. Rakha, H.; Ahn, K.; Trani, A. Development of VT-Micro model for estimating hot stabilized light duty vehicle and truck emissions. Transp. Res. Part D Transp. Environ. 2004, 9, 49-74. [CrossRef]

13. Sjödin, Å.; Andréasson, K. Multi-year remote-sensing measurements of gasoline light-duty vehicle emissions on a freeway ramp. Atmos. Environ. 2000, 34, 4657-4665. [CrossRef]

14. Gallus, J.; Kirchner, U.; Vogt, R.; Benter, T. Impact of driving style and road grade on gaseous exhaust emissions of passenger vehicles measured by a Portable Emission Measurement System (PEMS). Transp. Res. Part D Transp. Environ. 2017, 52, 215-226. [CrossRef]

15. Liu, H.; Rodgers, M.O.; Guensler, R. Impact of road grade on vehicle speed-acceleration distribution, emissions and dispersion modeling on freeways. Transp. Res. Part D Transp. Environ. 2019, 69, 107-122. [CrossRef]

16. TDOT. Road Design Manual. Available online: http://onlinemanuals.txdot.gov/txdotmanuals/rdw/index.htm (accessed on 31 March 2020).

17. Jun, J.; Guensler, R.; Ogle, J.H. Smoothing Methods to Minimize Impact of Global Positioning System Random Error on Travel Distance, Speed, and Acceleration Profile Estimates. Transp. Res. Rec. 2006, 1972, 141-150. [CrossRef]

18. Knott, G.D. Interpolating Cubic Splines; Springer Science \& Business Media: Berlin/Heidelberg, Germany, 2012; Volume 18.

19. ESRI. ArcGIS. Available online: https://www.esri.com/en-us/arcgis/about-arcgis/overview (accessed on 31 March 2020).

20. The United States Census. TIGER/Line Shapefile. Available online: https:/www.census.gov/geographies/ mapping-files/time-series/geo/tiger-line-file.html (accessed on 31 March 2020).

21. Default Age Distribution for MOVES. Available online: http://www.epa.gov/OMS/models/moves/documents/ default-age-distribution-tool-moves2014.xlsx (accessed on 31 March 2020).

22. MySQL. Available online: https://www.mysql.com/ (accessed on 31 March 2020).

23. LOESS. LOcally Estimated Scatterplot Smoothing. Available online: https://www.epa.gov/sites/production/ files/2016-07/documents/loess-lowess.pdf (accessed on 31 March 2020). 